İşletme Akademisi Dergisi
2020, $1(4): 324-343$
DOI:10.26677/TR1010.2020.628
Dergi web sayfasi: www.isakder.org

Araștırma Makalesi

\title{
Gayrimenkul Geliştirme Sürecinde Yeşil Bina Sertifika Sistemleri ve Türkiye Pratiği*
}

\section{Çağrı DENİZ}

Ankara Hacı Bayram Veli Üniversitesi, Lisansüstü Eğitim Enstitüsü, Taşınmaz Geliştirme Anabilim dall, Ankara.

cagri.deniz@hbv.edu.tr www.orcid.org/0000-0002-9515-7865

\section{Doç. Dr. Ender GÜLER}

Ankara Hacı Bayram Veli Üniversitesi, Tapu Kadastro Yüksekokulu, Emlak ve Emlak Yönetimi Bölümü, Ankara

ender.guler@hbv.edu.tr, www.orcid.org/0000-0002-4770-4668

\section{Özet}

Çalışmanın amacı, gayrimenkul sektöründe sürdürülebilirliğin önemini vurgulamak ve Türkiye'deki yeşil bina uygulamalarının dayanağını inceleyerek yerel sertifika sistemi çalışmalarına katkı sağlamaktır. Çalışmada LEED sertifika sistemi ile B.E.S.T-Konut Sertifika sisteminin değerlendirme ve puanlama kriterleri esas alınarak bu sistemler nicel araştırma modeli olan karşılaştırma modeli ile incelenmektedir. Karşılaştırmalı analiz yöntemiyle elde edilen veriler sonucunda B.E.S.T-Konut sertifika sisteminin dünyada ve Türkiye'de kullanım alanı en yaygın sertifika sistemi olan LEED sertifika sistemine göre artı ve eksi yönleri tespit edilmektedir. Elde edilen bulgular neticesinde ulusal sertifika sisteminin geliştirilmesi, iyileştirilmesi ve sertifika sisteminin yasal altyapısı ile marka imajının artırılması için öneriler sunulmaktadir.

Anahtar Kelimeler: LEED, B.E.S.T-Konut, Yeşil Bina, Gayrimenkul Geliştirme

Makale Gönderme Tarihi: 28.11.2020

Makale Kabul Tarihi: 06.12.2020

*Bu çalışma "Gayrimenkul Geliştirme Sürecinde Yeşil Bina Sertifika Sistemleri ve Türkiye Pratiği" isimli tezden türetilmiştir.

\section{Önerilen Atıf:}

Deniz, Ç. ve Güler, E., (2020). Gayrimenkul Geliştirme Sürecinde Yeşil Bina Sertifika Sistemleri ve Türkiye Pratiği, İsletme Akademisi Dergisi, 1(4): 324-343.

(C) 2020 İşletme Akademisi Dergisi. 


Journal of Business Academy
2020,1 (4): $324-3$
DOI:10.26677/TR1010.2020.628
Web pages: www.isakder.org

Research Article

\title{
Green Building Certificade Systems in the Process of Real Estate Devolopment and Turkey
}

\section{Çağrı DENiz}

Ankara Hacı Bayram Veli University, Institute of Graduate Studie, Ankara. cagri.deniz@hbv.edu.tr www.orcid.org/0000-0002-9515-7865

\section{Doç. Dr. Ender GÜLER}

Ankara Hacı Bayram Veli University, Academy of Land Registry and Cadastre, Ankara. ender.guler@hbv.edu.tr, www.orcid.org/0000-0002-4770-4668

\begin{abstract}
This study aimed that contributing to study of domestic certificate system with analyzing basis of green buildings practices thus it highlighted to importance of sustainability in real estate sector. In this research, researcher used comparative method which is subtype of qualitative method in the light of assessment and scoring criterias of LEED certificate system and B.E.S.Tproperty certificate system. The data which acquired with comparative analysis method are Showed B.E.S.T- property certificate system is the more commonly use than LEED certificate system in not only Turkey but also the World. Besides that study also compared two certificate system and tried to find out pluses and minuses of former than latter. In the light of findings, this study suggested proposal to enhancing and developing of national certificate system besides that improving legal basis and brand image.
\end{abstract}

Keywords: Green Building, LEED, B.E.S.T-Konut, Real Estate Development

Received: 28.11 .2020

Accepted: 06.12.2020

\section{Suggested Citation:}

Deniz, Ç. ve Güler, E., (2020). Green Building Certificade Systems in the Process of Real Estate Devolopment and Turkey, Journal of Business Academy, 1(4): 324-343.

(C) 2020 Journal of Business Academy. 


\section{GİRIŞ̧}

Gayrimenkul geliştirme, sürdürülebilirlik ve yeşil bina kavramları birbirleriyle yakından ilişkilidir. Bu ilişkiyi genel bir çerçevede değerlendirmek kavramların ortak hedeflerini ortaya çıkarmakta ve her bir kavramın yeni bir sonuç doğurduğu ve çıkan sonucun yeni bir hedef oluşturduğu gerçeğini görmekte yardımcı olmaktadır.

Gayrimenkul geliştirme kavramı genel anlamda taşınmazın var olan durumunu verim, kalite ve yüksek kullanım kriterleri çerçevesinde ileriye taşımak amacıyla ortaya çıkmaktadır. Asıl hedef ise topraktan maksimum fayda ve minimum maliyet ile çevreye duyarlı ve sürdürülebilir projeler tasarlamaktır. Bu etkenlerin varlığı geçmişteki klasik gayrimenkul algısından farklı olarak yenilikçi bir bakış açısı ile sürece bakmayı gerektirmektedir.

Bu yenilikçi bakış açısı günümüzde sıkça karşımıza çıkan ve gereklilikten çok ihtiyaca dönüşen sürdürülebilirlik kavramını sürece eklemektedir. Sürdürülebilirlik kavramının gayrimenkul geliştirme ile ilişkisinin şehirlerin gelişimi ile ortaya çıtığ görülmektedir. Şehirler kaynak kullanımındaki etkisi üzerinden değerlendirildiğinde, sürdürülebilirliğin en etkin sağlanabileceği alanların ön sırasında olduğu gerçeği ile karşılaşılmaktadır. Hızla artan nüfus ve yapılaşma sürdürülebilir kent kavramı doğurmaktadır çünkü şehirler doğal varlıkların esas harcayıcisı konumundadır.

Binalar şehirlerde sürdürülebilirliğin uygulanmasındaki en önemli araçlardan birisidir. Gerek şehirlerin enerji ve malzeme tüketiminin merkezi olması gerekse şehirlerde yaşayan insanların küresel sürdürülebilirliğin sağlanması için önemli roller üstlenebilmesi, binaları şehirlerdeki sürdürülebilir gelişmenin önemli bir ortağı haline getirmektedir. Bu bakımdan yeşil binalar şehirlerin sürdürülebilir özellikleri taşımasına yardımcı olan ana etmendir.

\subsection{Yeşil Bina Kavramı ve Ortaya Çıkışı}

Yeşil bina kavramı birçok kaynakta farklı şekillerde tanımlanmaktadır. Dünya genelinde kabul görmüş kesin bir tanımının olmaması, yeşil bina kavramının kendini sürekli güncelleyip geliştirmesinden kaynaklanmaktadır. Literatürde yer alan tanımlamalar ve yeşil bina kavramının kapsamı aşağıda irdelenmiştir.

Birleşik Devletler Yeşil Bina Konseyi (USGBC)'ne göre, yeşil bina kavramı sektörde farklı boyutlarla tanımlanmaktadır. Sürdürülebilir tasarım ve yüksek performanslı bina şeklinde adlandırılan yeşil bina kavramı klasik binalara göre çevreye negatif etkisi daha düşük binalar olarak açıklanırken, diğer açıdan sürdürülebilir tasarım kavramının daha geniş kapsamlı olduğu ve yeşil bina kavramının bu tasarımın bir alt bileşeni olduğu da söylenmektedir (Yılmaz, Arditi ve Korkmaz, 2010).

Yeşil bina anlayışı sadece çevresel etkileri içinde barındıran bir bina yapımı olarak görülmemelidir. Geri dönüşüm ve yaşam döngüsü kavramlarını da içeren, mimari tasarımı ve kendine yetebilirlik kriterlerini de kapsayan bir sistemin uygulanabilirliğini belirten bir kavramdır (Özcan ve Temizcan, 2010).

Yeşil bina kavramı, çevresel, sosyal ve finansal sıkıntıların sürdürülebilir yapı ilkeleri kapsamında çözümüne destek amaçlı oluşan ve insan sağlığı odaklı tasarlanan yapılar olarak açıklanmaktadır (Şentürk, 2014).

USGBC'nin yayınladığı "LEED ve Yeşil Bina" kılavuzu yeşil binayı tanımlarken planlama, tasarım, inşaat, işletme ve bina ömrü bitiminde gerekli kısımların yenilenmesi ve tekrar kullanımını içerdiğini vurgular. Yeşil bina, ekolojik, sosyal ve finansal faydalar arasındaki etkin ve dinamik dengeyi sağlayan yapılar şeklinde açıklanmaktadır (Uğur ve Leblebici, 2015). 
Yeşil bina; enerji kaynaklarının etkin kullanımı ve kirlilik yayan unsurların azaltılması suretiyle insan ve çevre sağlığı açısından ortaya çıkan olumsuz etkilerin sınırlandırılması amacı doğrultusunda oluşturulan binadır ( Şentürk, 2014).

Türkiye'de 2007 yılında Dünya Yeşil Binalar Konseyi (WGBC) altında kurulan bir sivil toplum kuruluşu olan Çevre Dostu Binalar Derneği (ÇEDBIK)'in yeşil bina tanımı ise; "sürdürülebilir, ekolojik, yeşil, çevre dostu vb. pek çok isim altında karşımıza çıkan doğayla uyumlu yapılar, yapının arazi seçiminden başlayarak yaşam döngüsü çerçevesinde değerlendirildiği, bütüncül bir anlayışla ve sosyal ve çevresel sorumluluk bilinciyle tasarlandığı, iklim verilerine ve o yere özgü koşullara uygun, ihtiyacı kadar tüketen, yenilenebilir enerji kaynaklarına yönelmiş, doğal ve atık üretmeyen malzemelerin kullanıldığı, katılımı teşvik eden, ekosistemlere duyarlı yapılar olarak tarif edilebilir" şeklindedir (Leblebici ve Uğur, 2015).

Amerika Yeşil Binalar Derneği (USGBC) ise 1993 yılında devletten bağımsız kar amacı gütmeyen bir organizasyon olarak kurulmuştur. USGBC, 1998 yılında LEED (Enerji ve Çevresel Tasarımda Liderlik) adıyla bir yeşil bina sertifika sistemi oluşturmuştur. Yeşil binaların yaygınlaşmaya başlaması ile beraber birçok ülkede bölgesel şartlara uyumlu ulusal yeşil bina sertifika sistemleri oluşturulmuştur (Baştanoğlu, 2017).

Türkiye'de ise 2007 yllında Çevre Dostu Yeşil Binalar Derneği kar gütmeyen sivil bir örgüt olarak kurulmuştur. 2012 yılında Çevre Dostu Yeşil Binalar Derneği tarafından Türkiye'ye özel bir yeşil bina sertifikası çalışmalarına başlanmıştır. Diğer yandan Mimar Sinan Güzel Sanatlar Üniversitesi bünyesinde kurulan Yapı Uygulama ve Araştırma Merkezi'nin koordinasyonuyla Sürdürülebilir Enerji Etkin Binalar (SEEB-TR) sertifika sistemi oluşturma çalışmaları devam etmektedir. Çalışmanın ilerleyen bölümlerinde dünyada ve Türkiye'de kullanılan yeşil bina sertifika sistemleri detaylı olarak inceleneceği için burada genel süreçten bahsetmekle yetinilmiştir.

Yeşil binalar, sosyal ve çevresel sorumluluk anlayışıyla tasarlanan ve yaşam döngüsü boyunca çevreye ve insan sağlığına duyarlı binalardır. Yeşil binalar, çevre duyarlılığının yanı sıra maliyet, sağlam yapı vb. kriterleri de içermektedir. Yeşil binalar aynı zamanda sürdürülebilir ya da yüksek performanslı binalar olarak adlandırılmaktadır. Yeşil binaların ana hedefleri:

- Esnek ve değişen koşullara uyum sağlayabilen, uzun kullanım ömrü olan binaların tasarlanması,

- Enerjinin verimli kullanılması,

- Kaynakların etkin kullanılması,

- Atıkların azaltılması,

- Temiz su kaynaklarının korunması,

- Zararlı ve tehlike arz eden maddelerden kaçınılması,

- Sağlık ve güvenlik risklerinin en aza indirilmesi,

- Sağliklı iç mekân hava kalitesi sağlanması,

- Biyolojik çeşitliliğin korunması

olarak açiklanabilir (Arslan N.C., 2015).

\subsection{Yeşil Binaların Gayrimenkul Sektörü Açısından Önemi}

Yeşil binaların yaygınlaşması, gayrimenkul sektöründe önemli bir yer edinmesine neden olmuştur. İnşaat sektöründe yer alan firmalar ile yapılan anket çalışması sonucunda ankete katılanların \%47'sinin, projelerinin büyük bir çoğunluğunun 2021 yılına kadar çevre dostu olmasını beklediğini ortaya koymuştur. Ankete $80^{\prime}$ den fazla ülkede 2000'i aşkın inşaat yetkilisi katılmıştır. Verilen bilgiye göre bazı bölgelerde talepler ikiye katlanmıştır. Bu talep patlamasının nedenleri olarak müşteri talepleri, çevresel düzenlemeler ve daha sağlıklı bina ve pazar talepleri 
etkili olmuştur. 2012 yılından beri yükseliş gösteren yeşil bina kavramı, arkasında yükselen bir ticari fayda da sağlamaktadır. Bu ticari faydalar \%8'lik işletme maliyet tasarrufu ve yeni yapılan yeşil binalar için \%7'lik artan bina değeridir. (Dodge, 2018).

Yapılan araştırmalar yeşil binaların daha az işletme masrafı olduğu daha hızlı ve yüksek değerlere kiralandığı ve satıldığını göstermektedir (WGBC, 2013). Bu nedenle yeşil binalar gayrimenkul geliştiricilerine cazip gelmektedir. Diğer yandan da yeşil binaların ilk yatırım maliyeti inşaat sektörünün önündeki en büyük engel olarak düşünülmektedir (Dodge, 2018). Genellikle tüketici tarafından talep edildikçe yapılmakta olan yeşil binalar, gelişen süreçte giderek azalış gösteren ilk yatırım maliyeti sebebi ile yaygınlaşma oranında artış sağlamaktadır.

Gelişmiş ülkelerde yeşil bina sistemlerinde verilen önem oldukça yüksektir. Yatırımcıyı ve tüketiciyi bu alana çekmek ve yeşil bina sistemlerinin yaygınlaştırılmasını sağlamak amacıyla devletler bu konu özelinde yönetmelikler çıkarmakta ve vergi teşvikleri ile süreci desteklemektedir. Türkiye'de 1 Ocak 2011 yılında çıkartılan Binalarda Enerji Performansı Yönetmeliği, 2011 yılından itibaren $50 \mathrm{~m}^{2}$ den büyük bütün yeni inşa edilmiş binaların ve 2017 yılından itibaren bütün mevcut binaların enerji kimlik belgesi almasını zorunlu kılmaktadır. 2011 yılı öncesi binalar için 02.05.2017 tarihine kadar alınması gereken enerji kimlik belgesi sürecin verimli yönetilememesinden kaynaklı olarak 2020 tarihine kadar uzatılmıştır.

\subsection{LEED Sertifika Sistemi}

LEED, 1998 yılında ABD'de USGBC (Amerikan Yeşil Binalar Derneği) tarafından kurulan ve 1990 yılında İngiltere'de ortaya çıkan BREEAM sertifika sisteminden sonra kapsamlı şekilde oluşturulan ikinci sertifika sistemidir. Günümüzde dünyada en çok kullanılan sertifika sistemi olması, sistemin her ülke şartları ve kanunlarına uyumlu bir sistem üzerine kurulmasından kaynaklanmaktadır.

LEED sisteminin işletilmesini sağlayan ekip içerisinde sektörden insanlar, akademisyenler ve alanında uzman personeller bulunmaktadır. Bu programın amacı, yapı sektöründe payı olan tüm kişi ve kuruluşların, binaların yaşam döngüsü süresince oluşturdukları çevresel etkilere dikkat çekerek, faaliyetlerini ve ürünlerini bu etkileri azaltmak doğrultusunda geliştirmeleridir (Baştanoğlu, 2017). USGBC çatısı altında sürdürülen bu sertifika sisteminde her bina tiplerine ve kullanım şekillerine göre uyarlanmış sertifika türleri bulunmaktadır. Bu sertifika türlerinde alanında uzman ekipler çalışmakta ve her geçen gün kendini yenileyen ve sistemin geliştirilmesi için yeni bakış açıları ve projeler sunan çalışmalar yapmaktadır. Versiyon yenilenmesi şeklinde ilerleyen bu süreç, 2000 yılında 2.0, 2009 yılında 3.0 versiyonları ile yaygınlık kazanmıştır. Her yeni versiyonda çevresel etkilerden dolayı güncellenen gereksinimleri sisteme entegre eden bu sistem 2016 yılında versiyon 4 ile dinamik bir yapı oluşturmuştur. İlerleyen dönemlerdeki versiyonlarındaki amaç çevreye sıfır zarardan ziyade çevreye pozitif etki sunmak olan LEED, sektörün de ilerlemesine katkı sunmaktadır.

Amerikan Yeşil Binalar Konseyi (USGBC) 2018 yılı için ABD dışında, LEED Sertifikalı binalar için ilk on ülke/bölge listesini yayınlamıştır. Liste insanlar için daha sağlıklı olan, daha az enerji, su tüketen, karbon salınımlarını azaltan, ailelere ve yatırımcılara para kazandıran yapılı çevreleri sunan pazarları sıralamaktadır. Türkiye LEED belgesi almış 337 proje, 10,9 milyon metrekare yapı alanıyla ile listede altıncı sırada yer almaktadır. Liste, 31-Aralık-2018 tarihi itibariyle ülkeleri LEED belgelendirilmesi yapılmış toplam brüt milyon metrekare yapı alanı üzerinden sıralamakta ve listedeki toplam 7.797 proje 210 milyon metrekareden fazla yapı alanını kapsamaktadır (USGBC, 2018). 2019 Ağustos ayı itibariyle Türkiye'de güncel sertifikalandırılmış proje sayısı 388 olmuştur (ÇEDBİK, 2019). 
Açılımı Enerji ve Çevre Tasarımı için Liderlik olan LEED, bugüne kadar 167 ülkede, 96.275 belgelenmiş kayıtlı proje ile Dünya'da en yaygın olarak kullanılan çevre dostu yeşil bina belgeleme programıdır. Yaygın olmasının nedenleri arasında uluslararası bilinirliği ve ABD içerisindeki projelerde sağlanan hukuksal destek ve teşvikler ön plana çıkmaktadır.

LEED değerlendirme süreci proje kaydının yapılması ile başlamaktadır. LEED'de denetlemeyi sadece USGBC yapmaktadır. Sertifikanın geçerliliği konusunda USGBC'nin bir sınırlaması bulunmamakta ve sertifika bir kere alındıktan sonra tekrar alınması gerekmemektedir ( Somalı, Ilicalı, 2009).

LEED değerlendirme süreci yapının/projenin USGBC'ye kaydettirilmesiyle başlamakta, yapının değerlendirmeye alınabilmesi için gerekli ön koşulları sağlayıp sağlamadığı kontrol edildikten sonra değerlendirme süreci başlamakta veya sonlanmaktadır. Gerekli koşulların sağlandığı varsayılarak, bir sonraki aşamada tasarım ve yapım olmak üzere iki aşamada yapının sağladığı ölçütlere ilişkin gerekli belgeler internet ortamında sisteme yüklenmekte ve bu bilgiler USGBC tarafından kontrol edilmekte, gerek görüldüğü takdirde ek belge istenebilmektedir (Şenel, 2010).

İstenilen ek bilgileri proje takımının 15 iş günü içerisinde göndermesi gerekmektedir. Belgelerin tamamlanıp gönderilmesinden sonra ise final değerlendirilmesi yapılır ve sertifika düzeyi belirlenerek başvuru yapan yetkiliye sonuç bildirilir. Bu kısımda proje sahibi değerlendirme sonucunu kabul edebilir veya itiraz hakkını kullanabilir. İtirazlardan sonra, yapı bu sonuçlara göre sertifikalandırılmış olur.

LEED 4 farklı sertifika (Altın, Platin, Gümüş ve LEED Sertifikası) sınıfına sahip olup binanın aldığı puanlara göre değerlendirilmesi yapılmaktadır ve sertifika geçerlilik süresinde bir sınırlama yoktur. Farklı sertifikasyon sınıflandırmaları aşağıda gösterilmiştir:

LEED, projeyi 110 puan üzerinden değerlendirmektedir ve alınan puan sayısına göre sertifika seviyesi belirlenmektedir. Dört farklı sertifika seviyesi vardır:

- LEED Certified (Sertifikalı): 40-49 puan

- LEED Silver (Gümüş): 50-59 puan

- LEED Gold (Altın): 60-79 puan

- LEED Platinum (Platin): 80 puan ve üzeri

LEED değerlendirmesi yapılırken dokuz temel kategori üzerinden işlemler ilerlemektedir. 2016 yılı öncesi altı kategori iken versiyon 4 ile birlikte üç yeni kategori daha eklenmiş ve puanlama buna göre yapılmıştır. Bu kategoriler aşağıdaki gibidir:

1. Bütünleşik Tasarım

2. Sürdürülebilir Arazi Seçimi ve Ulaşım Planlaması

3. Sürdürülebilir Araziler

4. Su Verimliliğ $i$

5. Malzeme ve Kaynaklar

6. Enerji ve Atmosfer

7. İç Çevre/Hava Kalitesi

8. Tasarımda Yenilik

9. Bölgesel Öncelik 
Tablo 1.1: LEED sertifikasyon sisteminin puan yüzdelerinin alt başlıkları.

\begin{tabular}{|c|c|}
\hline LEED Kriterleri & Puan \\
\hline \multicolumn{2}{|l|}{ SÜRDÜRÜLEBİLİR ARSA } \\
\hline Arsa Seçimi & 1 \\
\hline Yapı Çevresi Yoğunluğu & 5 \\
\hline Kirli Arazi İyileştirilmesi & 1 \\
\hline Alternatif Ulaşım - Toplu Taşıma & 6 \\
\hline $\begin{array}{l}\text { Alternatif Ulaşım - Bisiklet Yerleri ve Soyunma } \\
\text { Odaları }\end{array}$ & 1 \\
\hline $\begin{array}{l}\text { Alternatif Ulaşım - Düşük Salımlı ve Yakıt } \\
\text { Verimli Araçlar }\end{array}$ & 3 \\
\hline Alternatif Ulaşım - Otopark Kapasitesi & 2 \\
\hline $\begin{array}{l}\text { Arsa Geliştirme - Habitat Koruma ya da } \\
\text { Yenileme }\end{array}$ & 1 \\
\hline Arsa Geliştirme - Maksimum Açık Alan & 1 \\
\hline Yağmur Suyu Tasarımı - Miktar Kontrolü & 1 \\
\hline Yağmur Suyu Tasarımı - Kalite Kontrolü & 1 \\
\hline Is1 Adası Etkisi - Çatı Harici & 1 \\
\hline Is1 Adası Etkisi - Çatı & 1 \\
\hline \multirow[t]{2}{*}{ Işı1k Kirliliği } & 1 \\
\hline & am: 26 \\
\hline \multicolumn{2}{|l|}{ ENERJİ ve ATMOSFER } \\
\hline Optimum Enerji Performansı & 19 \\
\hline Tesis-içi Yenilenebilir Enerji & 7 \\
\hline Gelişmiş Test ve Devreye Alma & 2 \\
\hline Gelişmiş Soğutucu Yönetimi & 2 \\
\hline Ölçme ve Doğrulama & 3 \\
\hline Yeşil Enerji & 2 \\
\hline \multicolumn{2}{|c|}{ Toplam: 35} \\
\hline \multicolumn{2}{|l|}{ MALZEME ve KAYNAKLAR } \\
\hline $\begin{array}{l}\text { Binanın Tekrar Kullanımı - Duvar, Döşeme ve } \\
\text { Çatı }\end{array}$ & 4 \\
\hline İnşaat Esnası Atık Yönetimi & 2 \\
\hline Malzemenin Yeniden Kullanımı & 2 \\
\hline Geri Dönüştürülmüş İçerik & 2 \\
\hline Yerel Malzemeler & 2 \\
\hline Hizla Yenilenebilen Malzemeler & 1 \\
\hline Sertifikalı Ahşap & 1 \\
\hline
\end{tabular}

\begin{tabular}{|c|c|}
\hline LEED Kriterleri & Puan \\
\hline \multicolumn{2}{|l|}{ SU VERIMLILIIĞİ } \\
\hline Su Verimli Peyzaj & 4 \\
\hline Yenilikçi Atık Su Teknolojileri & 2 \\
\hline Su Tüketimi Azaltma & 4 \\
\hline \multicolumn{2}{|c|}{ Toplam: 10} \\
\hline \multicolumn{2}{|l|}{ İÇ ORTAM KALİTESİ } \\
\hline Temiz Hava Takibi & 1 \\
\hline Arttırılmış Havalandırma & 1 \\
\hline İnşaat Esnası İç Hava Kalitesi & 1 \\
\hline İnşaat Sonrası İç Hava Kalitesi & 1 \\
\hline $\begin{array}{l}\text { Düşük Salımlı Malzemeler - Yapıştırıcı ve } \\
\text { Astarlar }\end{array}$ & 1 \\
\hline $\begin{array}{l}\text { Düşük Salımlı Malzemeler - Boya ve } \\
\text { Kaplamalar }\end{array}$ & 1 \\
\hline Düşük Salımlı Malzemeler - Zemin Kaplamaları & 1 \\
\hline $\begin{array}{l}\text { Düš̈uk Salımlı Malzemeler - Kompozit Ahşap } \\
\text { Ürünler }\end{array}$ & 1 \\
\hline Kimyasal ve Kirletici Kontrolü & 1 \\
\hline Sistemlerin Kontrolü - Aydınlatma & 1 \\
\hline Sistemlerin Kontrolü - Is11 Konfor & 1 \\
\hline Isı1 Konfor - Tasarım & 1 \\
\hline Is1l Konfor - Onay & 1 \\
\hline Gün Işığı & 1 \\
\hline Görüş & 1 \\
\hline & am: 15 \\
\hline \multicolumn{2}{|l|}{ INOVASYON ve YEREL ÖNCELIIK } \\
\hline Tasarımda İnovasyon & 5 \\
\hline LEED Akredite Profesyonel & 1 \\
\hline Yerel Öncelik & 4 \\
\hline \multicolumn{2}{|c|}{ Toplam: 10} \\
\hline GENEL TOPI & M: 110 \\
\hline
\end{tabular}




\section{LEED Sertifikasyon Sinıflandırma Sistemi}

Yeni Binalar ve Önemli Restorasyonlar (NC: New Construction \& Major Renovations)

Var olan Binalar: Operasyon ve Bakım (EBOM: LEED Existing Building: Operations\& Maintenanc)

Ticari İç Mekanlar (CI: Commercial Interiors)

Kabuk ve Temel (CS: Core \& Shell

Okullar (LEED for Schools)

Perakende Mağazalar (LEED for Retail)

Hastaneler (LEED for Healthcare Centers)

Konutlar (LEED for Homes)

Mahalle Gelişimi (LEED for Neighborhood Development)

\subsection{B.E.S.T-Konut Sertifikası}

1990'lı yıların başından itibaren yaygınlaşmaya başlayan yeşil bina kavramı belirli kriter ve standartları da beraberinde getirmiştir. Bu kriter ve standartların bir sonucu olarak da yeşil bina sertifika sistemleri ortaya çıkmıştır. Bu sertifika sistemlerindeki kriterler genel hatları ile benzerlik gösterse de ülkeden ülkeye farklılıklar da içermektedir. Bazı sertifika sistemlerinde her ölçüte eşit puan tanınması, koşulları farklı ülkelerde değerlendirme yapmayı gerçekçi kılmamaktadır. Ülkeler için öncelikler farklı olabilmekte, bazıları için su tasarrufu ön planda iken bazı ülkeler için enerji korunumu, arsa kullanımı gibi konular ön plana çıkmaktadır.

Bu bağlamda her ülkenin kendi coğrafi, iklim, sosyolojik ve kültürel durumuna göre kriterlerini belirleyeceği ve bu kriterlere göre değerlendirme yapacağı sistemlerin varlığı öne çıkmaktadır. Bunun gerekliliğinin bir sonucu olarak ülkemizde bu alanda çalışmalara, 2007 yılı itibariyle Çevre Dostu Yeşil Binalar Derneği liderlik etmiştir.

Dünya Yeşil Binalar Konseyi üyesi Çedbik öncülügünde yüzden fazla paydaş ve akademisyen tarafından, LEED, BREEAM, DGNB vb. uluslararası sertifika sistemleri örnek alınarak, yeni Konut projeleri için B.E.S.T-KONUT Sertifika Sistemi oluşturulmuştur. Mevcut binalar, hastaneler vb. yapılar için kılavuz hazırlama çalışmaları ise devam etmektedir. Konut Kılavuzu kapsamında değerlendirilen ana başlıklar şunlardır:

1. Bütünleşik yeşil proje yönetimi

2. Arazi kullanımı

3. Su kullanımı

4. Enerji kullanımı

5. Sağlık ve konfor

6. Malzeme ve kaynak kullanımı

7. Konutta yaşam

8. İşletme ve bakım

9. Yenilikçilik 
Tablo 1.2: B.E.S.T-Konut sertifikasyon sisteminin puan yüzdelerinin alt başlıkları

\begin{tabular}{|c|c|}
\hline BEST-Konut Kriterleri & Puan \\
\hline \multicolumn{2}{|l|}{ Bütünleşik Yeşil Proje Yönetimi } \\
\hline Entegre Tasarım & 2 \\
\hline Çevreye Duyarlı Müteahhit & 2 \\
\hline İnşaat Atık Yönetimi & 3 \\
\hline \multirow[t]{2}{*}{ Gürültü Kirliliğgi } & 2 \\
\hline & Toplam: 9 \\
\hline \multicolumn{2}{|l|}{ Arazi Kullanımı } \\
\hline Araziye Yerleşim & 3 \\
\hline Afet Riski & 3 \\
\hline Yoğunluk ve Konut Yapısı İlişkisi & 2 \\
\hline Arazinin Yeniden Kullanımı & 3 \\
\hline \multirow[t]{2}{*}{ Kentsel Donatılara Yakınlık } & 2 \\
\hline & Toplam: 13 \\
\hline \multicolumn{2}{|l|}{ Su Kullanımı } \\
\hline \multicolumn{2}{|l|}{ Önkoşul: Su Kullanımını Azaltma } \\
\hline Su Kullanımını Azaltma & 6 \\
\hline Su Kayıplarını Önlemek & 2 \\
\hline Atık Su Arıtma ve Değerlendirme & 2 \\
\hline \multirow{2}{*}{ Yüzeysel Su Akışı } & 2 \\
\hline & Toplam: 12 \\
\hline \multicolumn{2}{|l|}{ Enerji Kullanımı } \\
\hline $\begin{array}{l}\text { Önkoşul 1: Bina Enerji Sistemleri Kontrol - } \\
\text { İşetmeye Alma - Kabul Süreci }\end{array}$ & \\
\hline \multicolumn{2}{|l|}{ Önkoşul 2: Enerji Verimliliği } \\
\hline Enerji Verimliliği & 15 \\
\hline Yenilenebilir Enerji Kullanımı & 7 \\
\hline Diș Aydınlatma & 1 \\
\hline Enerji Verimli Beyaz Eşyalar & 2 \\
\hline \multirow[t]{2}{*}{ Asansörler } & 1 \\
\hline & Toplam: 26 \\
\hline \multicolumn{2}{|l|}{ Yenilikçilik } \\
\hline Yenilikçilik & 1 \\
\hline Onaylı Danıșman & 1 \\
\hline & Toplam: 2 \\
\hline
\end{tabular}

\begin{tabular}{|c|c|}
\hline BEST-Konut Kriterleri & Puan \\
\hline \multicolumn{2}{|l|}{ Malzeme ve Kaynak Kullanımı } \\
\hline Çevre Dostu Malzeme Kullanımı & 3 \\
\hline Mevcut Bina Elemanlarından Yararlanılması & 3 \\
\hline Malzemelerin Yeniden Kullanımı & 3 \\
\hline Yerel Malzeme Kullanımı & 3 \\
\hline \multirow[t]{2}{*}{ Dayanıklı Malzeme } & 2 \\
\hline & lam: 14 \\
\hline \multicolumn{2}{|l|}{ Sağlık ve Konfor } \\
\hline Is1l Konfor & 3 \\
\hline Görsel Konfor & 3 \\
\hline Taze Hava & 3 \\
\hline Kirleticilerin Kontrolü & 2 \\
\hline \multirow[t]{2}{*}{ İşitsel Konfor } & 3 \\
\hline & lam: 14 \\
\hline \multicolumn{2}{|l|}{ Konutta Yaşam } \\
\hline Evrensel ve Kapsayıcı Tasarım & 2 \\
\hline Güvenlik & 2 \\
\hline Spor ve Dinlenme Alanı & 2 \\
\hline Sanat & 1 \\
\hline Ulaşım & 3 \\
\hline Otopark Alanı & 2 \\
\hline \multirow[t]{2}{*}{ Evden Çalışma } & 2 \\
\hline & lam: 14 \\
\hline \multicolumn{2}{|l|}{ İşletme ve Bakım } \\
\hline $\begin{array}{l}\text { Atıkların Yerinde Ayrılması ve Kullanıcı } \\
\text { Erisimi }\end{array}$ & 2 \\
\hline Atık Teknolojileri & 1 \\
\hline Bina Kullanım ve Bakım Klavuzu & 1 \\
\hline \multirow[t]{2}{*}{ Tüketim Değerlerinin Takibi } & 2 \\
\hline & plam: 6 \\
\hline GENEL TC & M: 110 \\
\hline
\end{tabular}


B.E.S.T-Konut sertifika süreci aşağıdaki gibidir;

- B.E.S.T-Konut sertifikasına yeni bina yapmak isteyen her ilgili başvuru yapabilmektedir. Hazırlanan proje yerel yönetmeliklere ve ilgili belediyenin imar yönetmeliklerine uygun olarak hazırlanır. Ayrıca imar planlarına da uygun olması gereklidir. İlgililer eğer projeleri hâlihazırda tasarım aşamasında ise, bu projeleri için tasarım uygunluk yazısı da talep edebilmektedir. Tasarımda uygunluk yazısı talep edilen projelerde kriterler içerisinde belirlenen ön koşulların tamamı yerine getirilmeli ve tasarımda kriter puanlamasından en az on beş puan alınması gerekmektedir.

- "B.E.S.T-Konut Sertifika" değerlendirme esasları "B.E.S.T-Konut Sertifika Yönetmeliği" ile açıklanmıştır. Sertifika talebi ve ön başvuru aşamalarını geçen ilgililer, kılavuz esas alınarak hazırlanmış proje dosyaları ile birlikte sertifika başvuru işlemini gerçekleştirirler. Proje dosyası üzerinden yapılacak olan değerlendirme kılavuzda belirtilen ve dokuz kriter ve kırk dört alt başlıktan oluşan puanlama tablosu esas alınarak yapılır. Bu puanlama alanında uzman çalışma ekibi tarafından bağımsız ve gerçek ölçütler baz alınarak hesaplanır. Sertifika başvurunun olumlu sonuçlanması için asıl olan ön koşul ise iskân ruhsatının alınmış olmasıdır.

Yapılan literatür araştırması sonucunda elde edilen veriler neticesinde çalışma şu araştırma soruları üzerinde şekillenmektedir;

* Yeşil bina sertifika sistemlerinin kategorileri ve alt kredileri nasil belirlenmelidir?

* Sertifika sistemlerinin Türkiye'de yasal bir altyapısı var mı?

* Sertifika sistemlerinin denetlenebilirliği ne boyuttadır?

* Yeşil bina sertifikalı projeler prestij amaçlı mı yapılmakta yoksa bir gereklilikten mi ortaya çıkmaktadır?

* Ulusal yeşil bina sertifika sistemi kullanımının faydaları nelerdir?

\section{YÖNTEM}

Çalışmada; 'LEED Yeni Yapılar ve Büyük Yenilemeler v4.1' ile 'B.E.S.T-Konut Sertifikası Versiyon 2.0' kılavuzları kullanılmıştır. Amaçlı örnek olarak belirlenen, LEED ve B.E.S.T-Konut Sertifika Sistemlerine ilişkin değerlendirme ölçütleri ve sertifika düzeyleri, anılan sertifika sistemlerinin web sayfalarından elde edilen katalog verilerinin son versiyonları üzerinden içerik analizi yapılarak incelenmiştir. Her iki sertifika sistemine ait ana kategoriler ve alt krediler aynı tabloda (Tablo 2.1) gösterilmiş ve farklı kategorilerde olup aynı içeriğe sahip alt krediler tematik olarak renklendirilmiştir. Birbiriyle ilintili her ana başlık ayrıca karşılaştırmalı incelenmiştir. Çalışmada nicel araştırma yöntemi modeli olan karşılaştırma modeli kullanılmaktadır. 
Tablo2.1: LEED ve B.E.S.T-Konut sertifika sistemlerinin karşılaştırılması.
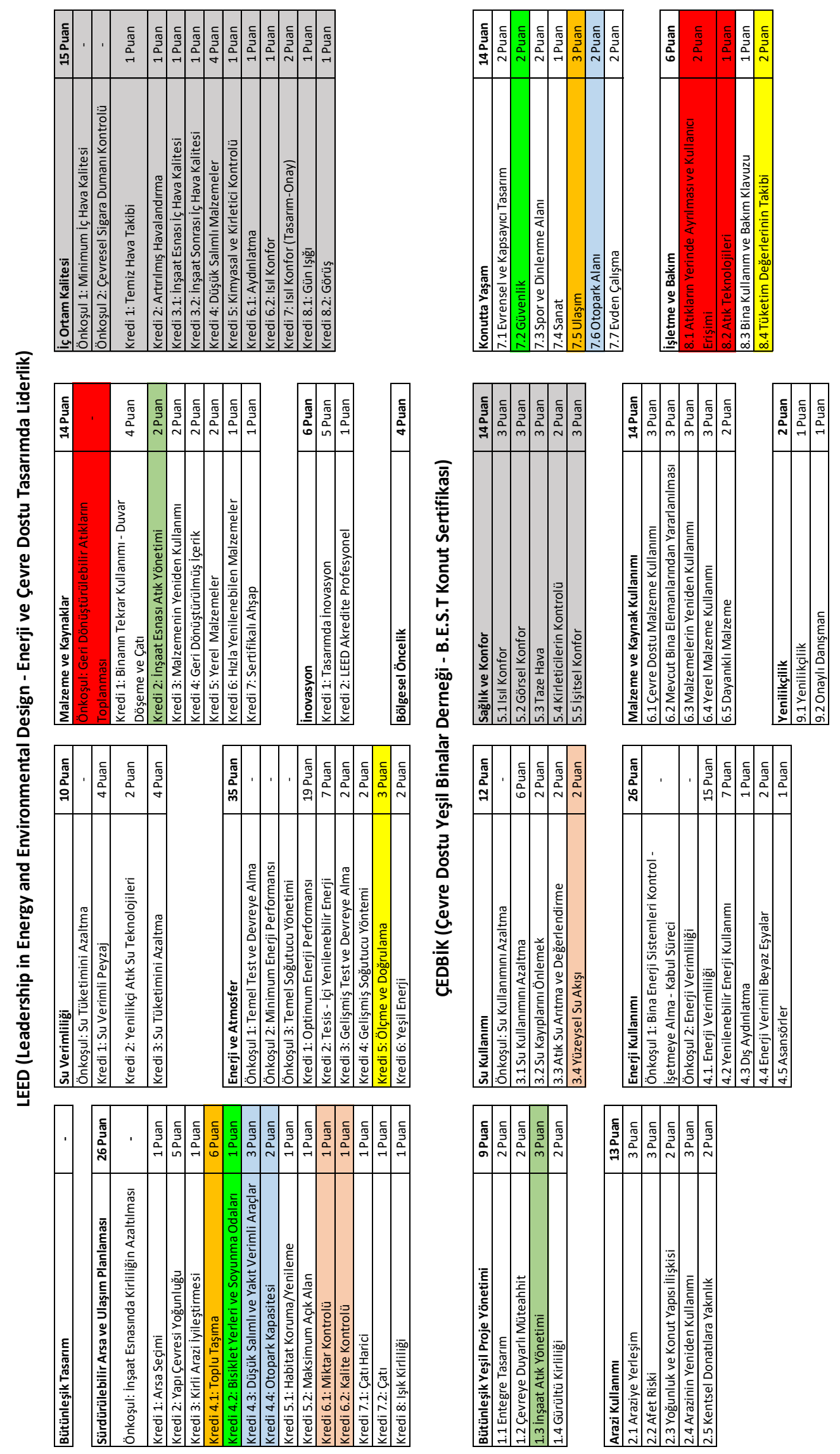
Burada LEED ve B.E.S.T.-Konut sertifikalarının puanlama tabloları yer almaktadır. Örneğin kırmızı renkle renklendirilmiş alanlarda LEED sertifikasında malzeme ve kaynaklar kategorisinde ön koşul olarak sunulan 'geri dönüştürülebilir atıkların toplanması' B.E.S.T.-Konut sertifikasında işletme ve bakım kategorisinde alt kredi olarak yer almaktadır. Veya LEED sertifikasında 'iç ortam kalitesi' kategorisi ile B.E.S.T.-Konut'un 'sağlık ve konfor' kategorisi ile benzerdir.

Bu tablodaki kategoriler ve alt krediler detaylı olarak incelenmiştir.

\section{BULGULAR}

Bu tablodaki kategoriler ve alt krediler detaylı olarak incelenmiştir.

\section{Bütünleșik (Entegre) Tasarm:}

Tablo 3.1: LEED ve B.E.S.T-Konut sertifikası bütünleşik tasarım kategorisi karşılaştırması

\begin{tabular}{|l|l|}
\hline LEED & PUAN \\
\hline Bütünleşik Tasarım & - \\
\hline
\end{tabular}

\begin{tabular}{|l|l|}
\hline B.E.S.T.-Konut & PUAN \\
\hline Bütünleşik Yeşil Proje Yönetimi & 9 Puan \\
\hline 1.1 Entegre Tasarım & 2 Puan \\
\hline 1.2 Çevreye Duyarlı Müteahhit & 2 Puan \\
\hline 1.3 İnşaat Atık Yönetimi & 3 Puan \\
\hline 1.4 Gürültü Kirliliği & 2 Puan \\
\hline
\end{tabular}

Aslında sürdürülebilirliğin özünde, farklı ancak birbiriyle ilgili konuların bir arada değerlendirilmesi yatmaktadır. Bu başlıkta da farklı disiplinlerin entegre şekilde bir arada çalışması öngörülmüştür.

LEED sertifikasında bütünleşik tasarım için puan veya alt krediler ile çeşitli yükümlülükler getirilmemiş, kavramsal tanımlama yapılmıştır. Yani LEED için bu başlık bir önkoşul niteliğindedir. B.E.S.T.-Konut sertifikasında ise uzman kadro üzerinden (mimar, mühendis vb.) puan verilmektedir.

Çevreye duyarlı müteahhit kredisinde firmadan çevresel yönetim sertifikası istenmektedir. İnşaat atık yönetiminde ise inşaat atıklarının geri dönüşüm oranı \%45 olarak belirlenmişken LEED sertifikası bu konuyu malzeme ve kaynaklar kategorisinde bulunan inşaat esnası atık yönetiminde $\% 75$ oran ile belirlemiştir.

\section{Arazi Kullanımı:}

Tablo 2.2: LEED ve B.E.S.T-Konut sertifikası arazi kullanımı kategorisi karşılaştırması

\begin{tabular}{|l|l|}
\hline LEED & PUAN \\
\hline $\begin{array}{l}\text { Sürdürülebilir Arsa ve Ulaşım } \\
\text { Planlaması }\end{array}$ & 26 Puan \\
\hline $\begin{array}{l}\text { Önkoşul: İnşaat Esnasında } \\
\text { Kirliliğin Azaltılması }\end{array}$ & - \\
\hline Kredi 1: Arsa Seçimi & 1 Puan \\
\hline Kredi 2: Yapı Çevresi Yoğunluğu & 5 Puan \\
\hline Kredi 3: Kirli Arazi İileştirmesi & 1 Puan \\
\hline Kredi 4.1: Toplu Taşıma & 6 Puan \\
\hline
\end{tabular}

\begin{tabular}{|l|l|}
\hline $\begin{array}{l}\text { Kredi Habitat } \\
\text { Koruma/Yenileme }\end{array}$ & 1 Puan \\
\hline Kredi 5.2: Maksimum Açık Alan & 1 Puan \\
\hline Kredi 6.1: Miktar Kontrolü & 1 Puan \\
\hline Kredi 6.2: Kalite Kontrolü & 1 Puan \\
\hline Kredi 7.1: Çatı Harici & 1 Puan \\
\hline Kredi 7.2: Çatı & 1 Puan \\
\hline Kredi 8: Iş̧ı Kirliliği & 1 Puan \\
\hline
\end{tabular}




\begin{tabular}{|l|l|}
$\begin{array}{l}\text { Kredi 4.2: Bisiklet Yerleri ve } \\
\text { Soyunma Odaları }\end{array}$ & 1 Puan \\
\hline $\begin{array}{l}\text { Kredi 4.3: Düşük Salımlı ve Yakıt } \\
\text { Verimli Araçlar }\end{array}$ & 3 Puan \\
\hline Kredi 4.4: Otopark Kapasitesi & 2 Puan \\
\hline
\end{tabular}

\begin{tabular}{|l|l|}
\hline B.E.S.T.-Konut & PUAN \\
\hline Arazi Kullanımı & $\mathbf{1 3}$ Puan \\
\hline 2.1 Araziye Yerleşim & 3 Puan \\
\hline 2.2 Afet Riski & 3 Puan \\
\hline 2.3 Yoğunluk ve Konut Yapısı İlişkisi & 2 Puan \\
\hline 2.4 Arazinin Yeniden Kullanımı & 3 Puan \\
\hline 2.5 Kentsel Donatılara Yakınlık & 2 Puan \\
\hline
\end{tabular}

Bu başlık altında LEED sertifikasının ön koşul olarak sunduğu inşaat esnası kirlilik kontrolü B.E.S.T.-Konut sertifikasında tam anlamıla yer almamaktadır.

Kazanılan puanlar farklılık gösterse de genel hatları ile bu kategori iki sertifika sisteminde de yüksek benzerlik içermektedir. Ancak LEED sertifikasına kıyasla B.E.S.T.-Konut sertifikası üç başlıkta eksiklik içermektedir. Bunlar; LEED sertifikası kredi 5.1 ve 5.2' de çevre hassasiyeti içeren başlıklar, kredi 7.1 ve $7.2^{\prime}$ de bulunan çatıya ilişkin başlıklar ve kredi 8'deki ışık kirliliği başlığıdır. Bu başlıklar B.E.S.T.-Konut sertifikasında kendine yer bulamamaktadır.

\section{Su Kullanımı:}

Tablo 3.3: LEED ve B.E.S.T-Konut sertifikası su kullanımı kategorisi karşılaştırması

\begin{tabular}{|l|l|}
\hline LEED & PUAN \\
\hline Su Verimliliği & $\mathbf{1 0}$ Puan \\
\hline Önkoşul: Su Tüketimini Azaltma & - \\
\hline Kredi 1: Su Verimli Peyzaj & 4 Puan \\
\hline $\begin{array}{l}\text { Kredi 2: Yenilikçi Atık Su } \\
\text { Teknolojileri }\end{array}$ & 2 Puan \\
\hline Kredi 3: Su Tüketimini Azaltma & 4 Puan \\
\hline
\end{tabular}

\begin{tabular}{|l|l|}
\hline B.E.S.T.-Konut & PUAN \\
\hline Su Kullanımı & $\mathbf{1 2}$ Puan \\
\hline Önkoşul: Su Kullanımını Azaltma & - \\
\hline 3.1 Su Kullanımını Azaltma & 6 Puan \\
\hline $\begin{array}{l}\text { 3.2 Su Kayıplarını Önlemek } \\
\begin{array}{l}\text { 3.3 Atık Su Arıtma ve } \\
\text { Değerlendirme }\end{array}\end{array}$ & 2 Puan \\
\hline 3.4 Yüzeysel Su Akışı & 2 Puan \\
\hline
\end{tabular}

Bu kategoride iki sertifika sistemi de su kullanımını azaltma odaklı kriterler belirlemişlerdir. Oranlar değişiklik gösterse de iki sertifika sistemi de benzer değerlendirmelerde bulunmaktadır.

B.E.S.T.-Konut sertifikası kredi 3.2'de bulunan 'su kayıplarını önleme' başlığı ile LEED sertifikasından pozitif ayrışmaktadır. Bina su iletim hattındaki kaçakları tespit etmek amacıyla 
kaçak kontrol sistemi kurulması oldukça önemlidir. Dağıtım esnasında oluşan su kaybı gelişmiş ülkelerde \%8-10 arası iken Türkiye' de bu oran yaklaşı \%24'tür.

\section{Enerji Kullanımı:}

Tablo 3.4: LEED ve B.E.S.T-Konut sertifikası enerji kullanımı kategorisi karşılaştırması

\begin{tabular}{|c|c|c|c|}
\hline LEED & PUAN & B.E.S.T.-Konut & PUAN \\
\hline Enerji ve Atmosfer & 35 Puan & Enerji Kullanımı & 26 Puan \\
\hline $\begin{array}{l}\text { Önkoşul 1: Temel Test ve Devreye } \\
\text { Alma }\end{array}$ & - & \multirow{2}{*}{$\begin{array}{l}\text { Önkoşul 1: Bina Enerji Sistemleri } \\
\text { Kontrol - İşetmeye Alma - Kabul } \\
\text { Süreci }\end{array}$} & \multirow{2}{*}{-} \\
\hline $\begin{array}{l}\text { Önkoşul 2: Minimum Enerji } \\
\text { Performansı }\end{array}$ & - & & \\
\hline $\begin{array}{l}\text { Önkoşul 3: Temel Soğutucu } \\
\text { Yönetimi }\end{array}$ & - & Önkoşul 2: Enerji Verimliliği & - \\
\hline $\begin{array}{l}\text { Kredi 1: Optimum } \\
\text { Performansı }\end{array}$ & 19 Puan & 4.1. Enerji Verimliliği & 15 Puan \\
\hline $\begin{array}{l}\text { Kredi 2: Tesis - İçi Yenilenebilir } \\
\text { Enerji }\end{array}$ & 7 Puan & 4.2 Yenilenebilir Enerji Kullanımı & 7 Puan \\
\hline $\begin{array}{l}\text { Kredi 3: Gelişmiş Test ve Devreye } \\
\text { Alma }\end{array}$ & 2 Puan & 4.3 Dış Aydınlatma & 1 Puan \\
\hline $\begin{array}{l}\text { Kredi 4: Gelişmiş Soğutucu } \\
\text { Yöntemi }\end{array}$ & 2 Puan & 4.4 Enerji Verimli Beyaz Eşyalar & 2 Puan \\
\hline Kredi 5: Ölçme ve Doğrulama & 3 Puan & 4.5 Asansörler & 1 Puan \\
\hline Kredi 6: Yeşil Enerji & 2 Puan & & \\
\hline
\end{tabular}

Enerji kullanımı kategorisinde iki sertifika sistemi de temel enerji sistemlerini ve sağlanması gereken enerji verimliliğini ön koşul olarak sunmaktadır.

LEED sertifikası kredi 5'te bulunan ‘ölçme ve doğrulama' ile B.E.S.T.-Konut sertifikasında işletme ve bakım kategorisinde bulunan 'tüketim değerlerinin takibi' başlıkları binanın yaşamı boyunca enerji kullanımının kontrol altında tutulmasını sağlamaktadır.

İçerik konusunda ise;

- Bina soğutma alanında LEED sertifikası çeşitli kurallar getirmekte ve kredi 3 ve kredi 4'te klima sistemlerinde kullanılan zararlı gazları yasaklamaktadır. B.E.S.T.-Konut sertifikası ise bu konuya değinmemektedir.

- B.E.S.T.-Konut sertifikasında bulunan aydınlatma ve asansörlere yönelik az enerji tüketimi kriterleri ise LEED sertifikasında yer almamaktadır.

\section{Malzeme ve Kaynaklar:}

Tablo 3.5: LEED ve B.E.S.T-Konut sertifikası malzeme ve kaynaklar kategorisi karşılaştırması 


\begin{tabular}{|l|l|}
\hline LEED & PUAN \\
\hline Malzeme ve Kaynaklar & $\mathbf{1 4}$ Puan \\
\hline $\begin{array}{l}\text { Önkoşul: Geri Dönüştürülebilir } \\
\text { Atıkların Toplanması }\end{array}$ & - \\
\hline $\begin{array}{l}\text { Kredi 1: Binanın Tekrar Kullanımı - } \\
\text { Duvar Döşeme ve Çatı }\end{array}$ & 4 Puan \\
\hline Kredi 2: İnşaat Esnası Atık Yönetimi & 2 Puan \\
\hline $\begin{array}{l}\text { Kredi 3: Malzemenin Yeniden } \\
\text { Kullanımı }\end{array}$ & 2 Puan \\
\hline Kredi 4: Geri Dönüştürülmüş İçerik & 2 Puan \\
\hline Kredi 5: Yerel Malzemeler & 2 Puan \\
\hline $\begin{array}{l}\text { Kredi 6: Hızla Yenilenebilen } \\
\text { Malzemeler }\end{array}$ & 1 Puan \\
\hline Kredi 7: Sertifikalı Ahşap & 1 Puan \\
\hline
\end{tabular}

\begin{tabular}{|l|l|}
\hline B.E.S.T.-Konut & PUAN \\
\hline Malzeme ve Kaynak Kullanımı & 14 Puan \\
\hline $\begin{array}{l}\text { 6.1 Çevre Dostu Malzeme } \\
\text { Kullanımı }\end{array}$ & 3 Puan \\
\hline $\begin{array}{l}\text { 6.2 Mevcut Bina Elemanlarından } \\
\text { Yararlanılması }\end{array}$ & 3 Puan \\
\hline $\begin{array}{l}\text { 6.3 Malzemelerin Yeniden } \\
\text { Kullanımı }\end{array}$ & 3 Puan \\
\hline 6.4 Yerel Malzeme Kullanımı & 3 Puan \\
\hline 6.5 Dayanıklı Malzeme & 2 Puan \\
\hline
\end{tabular}

Bu kategoride LEED sertifikasının ön koşul olarak sunduğu kriter B.E.S.T.-Konut sertifikasında işletme ve bakım kategorisinde benzer şekilde kendine yer bulmaktadır.

Geri dönüştürülebilen malzemeler, atık teknolojileri, sertifikalı ürün kullanımı vb. kriterler iki sertifika sisteminde de benzer oranlardadır. Yerel malzeme kullanımında LEED sertifikası 800 kilometre yakınlığı, B.E.S.T.-Konut sertifikası ise 400 kilometre yakınlığı baz almaktadır.

\section{6. İç Ortam Kalitesi:}

Tablo3.6: LEED ve B.E.S.T-Konut sertifikası iç ortam kalitesi kategorisi karşılaştırması

\begin{tabular}{|l|l|}
\hline LEED & PUAN \\
\hline İç Ortam Kalitesi & $\mathbf{1 5}$ Puan \\
\hline $\begin{array}{l}\text { Önkoşul 1: Minimum İç Hava } \\
\text { Kalitesi }\end{array}$ & - \\
\hline $\begin{array}{l}\text { Önkoşul 2: Çevresel Sigara } \\
\text { Dumanı Kontrolü }\end{array}$ & - \\
\hline Kredi 1: Temiz Hava Takibi & 1 Puan \\
\hline Kredi 2: Artırılmış Havalandırma & 1 Puan \\
\hline $\begin{array}{l}\text { Kredi 3.2: İnşaat Sonrası İç Hava } \\
\text { Kalitesi }\end{array}$ & 1 Puan \\
\hline Kredi 4: Düşük Salımlı Malzemeler & 4 Puan \\
\hline
\end{tabular}

\begin{tabular}{|l|l|}
\hline $\begin{array}{l}\text { Kredi 5: Kimyasal ve Kirletici } \\
\text { Kontrolü }\end{array}$ & 1 Puan \\
\hline Kredi 6.1: Aydınlatma & 1 Puan \\
\hline Kredi 6.2: Isıl Konfor & 1 Puan \\
\hline $\begin{array}{l}\text { Kredi 7: Isıl Konfor (Tasarım- } \\
\text { Onay) }\end{array}$ & 2 Puan \\
\hline Kredi 8.1: Gün Işığı & 1 Puan \\
\hline Kredi 8.2: Görüş & 1 Puan \\
\hline
\end{tabular}




\begin{tabular}{|l|l|} 
Sağlık ve Konfor & $\mathbf{1 4}$ Puan \\
\hline 5.1 Isıl Konfor & 3 Puan \\
\hline 5.2 Görsel Konfor & 3 Puan \\
\hline 5.3 Taze Hava & 3 Puan \\
\hline 5.4 Kirleticilerin Kontrolü & 2 Puan \\
\hline 5.5 İşitsel Konfor & 3 Puan \\
\hline
\end{tabular}

Bu kategoride iki sertifika sistemi de bina içi temiz hava üzerine odaklanmış ve LEED sertifikası bunu ön koşul olarak kabul etmiştir. Belirli standartlar baz alınarak belirlenen bu kriterlerde standart üzeri temiz hava LEED sertifikasında puan kazandırırken B.E.S.T.-Konut sertifikasında standart düzeyinin sağlanması puan kazanmak için yeterli görülmektedir.

LEED sertifikası temiz hava takibi yaparken B.E.S.T.-Konut sertifikasında ileriye dönük bir kriter bulunmamaktadır.

LEED sertifikası çevresel sigara dumanı kontrolünü ön koşul olarak kabul ederken B.E.S.T.Konut sertifikasında dumansız hava sahası ile ilgili bir kriter bulunmamaktadır.

LEED sertifikası kredi 8.2'de düzenli kullanılan alanların minimum \%90'ında engel olmadan dışarısının görülebilir olması kriteri B.E.S.T.-Konut sertifikasında bulunmamaktadır.

\section{7. İnovasyon ve Yerel Öncelik:}

Tablo 3.7: LEED ve B.E.S.T-Konut sertifikası inovasyon ve yerel öncelik kategorisi karşılaştırması

\begin{tabular}{|l|l|}
\hline LEED & PUAN \\
\hline İnovasyon & 6 Puan \\
\hline Kredi 1: Tasarımda İnovasyon & 5 Puan \\
\hline $\begin{array}{l}\text { Kredi 2: LEED Akredite } \\
\text { Profesyonel }\end{array}$ & 1 Puan \\
\hline
\end{tabular}

\begin{tabular}{|l|l|}
\hline B.E.S.T.-Konut & PUAN \\
\hline Yenilikçilik & 2 Puan \\
\hline 9.1 Yenilikçilik & 1 Puan \\
\hline 9.2 Onaylı Danışman & 1 Puan \\
\hline
\end{tabular}

\begin{tabular}{|l|l|}
\hline LEED & PUAN \\
\hline Bölgesel Öncelik & 4 Puan \\
\hline
\end{tabular}

LEED sertifikasında bulunan 'tasarımda inovasyon' ve B.E.S.T.-Konut sertifikasında bulunan 'yenilikçilik' kredileri içerik olarak benzer ancak puanlama olarak farklıdır. Sertifika sistemlerinde bulunan ikinci krediler projenin başından sonuna kadar proje ekibinde akredite danışman gerekliliğinden bahsetmektedir.

LEED sertifika sistemi ‘bölgesel öncelik' kategorisi ile binanın bulunduğu bölgede öncelikli olan çevresel sorunlar ile ilgili kredilerin öneminin artırılması amaçlanmaktadır. B.E.S.T.-Konut sertifikası bölgesel öncelik konusuna değinmemektedir.

\section{B.E.S.T-Konut}

Konutta Yașam - İșletme ve Bakım 
Tablo 3.8: B.E.S.T-Konut sertifikası Konutta yaşam/işletme ve bakım kategorisi

\begin{tabular}{|l|l|}
\hline B.E.S.T.-Konut & PUAN \\
\hline Konutta Yaşam & 14 Puan \\
\hline 7.1 Evrensel ve Kapsayıcı Tasarım & 2 Puan \\
\hline 7.2 Güvenlik & 2 Puan \\
\hline 7.3 Spor ve Dinlenme Alanı & 2 Puan \\
\hline 7.4 Sanat & 1 Puan \\
\hline 7.5 Ulaşım & 3 Puan \\
\hline 7.6 Otopark Alanı & 2 Puan \\
\hline 7.7 Evden Çalışma & 2 Puan \\
\hline
\end{tabular}

\begin{tabular}{|l|l|}
\hline B.E.S.T.-Konut & PUAN \\
\hline İşletme ve Bakım & 6 Puan \\
\hline $\begin{array}{l}\text { 8.1 Atıkların Yerinde Ayrılması ve } \\
\text { Kullanıı Erişimi }\end{array}$ & 2 Puan \\
\hline 8.2 Atık Teknolojileri & Puan \\
\hline $\begin{array}{l}\text { 8.3 Bina Kullanım ve Bakım } \\
\text { Kılavuzu }\end{array}$ & 1 Puan \\
\hline 8.4 Tüketim Değerlerinin Takibi & 2 Puan \\
\hline
\end{tabular}

'Konutta yaşam' ile 'işletme ve bakım' kategorileri LEED sertifikasında yer almamakta, B.E.S.T.Konut sertifikasında ise iki kategori olarak ortaya çıkmaktadır.

İşletme ve bakım kategorisinde kredi 8.1'de karşımıza çıkan 'atıkların yerinde ayrılması ve kullanıcı erişimi' alt başlığı LEED sertifikasında malzeme ve kaynaklar kategorisinde ön koşul olarak karşımıza çıkmaktadır.

Kredi 8.2' de bulunan 'atık teknolojileri' alt başlığında puan alınabilmesi için kredi 8.1'in sağlanmış olması gerekmektedir. Burada kompost makinesi, dal öğütücü vb. atık ekipmanlarından bahsedilmektedir.

Kredi 8.3 'de bahsi geçen 'bina kullanıcı ve bakım kılavuzu' bina kullanıcısı için hazırlanan kılavuz ile kullanıcılara ilk ay içinde eğitim verilmesini içermektedir

\section{SONUÇ VE TARTIŞMA}

- B.E.S.T.-Konut sertifika programının ülkemizde kullanılmaya başlanması ile birlikte, günümüzde yaygın kullanımı olan LEED sertifika programından daha düşük maliyetlerle sertifikalandırma yapılabilmesi öngörülmektedir.

- Ulusal sertifika kullanımı ile birlikte sermayenin ülke içinde kalmasını sağlaması ve ülke ekonomisine katkı sağlanması beklenmektedir.

- LEED sertifika programının uluslararası bir sertifika programı olması onu kriterleri daha uygulanabilir ve esnek kılmaktadır.

- LEED sertifika programının yüksek marka değerine sahip olması firmaların bu sertifikayı tercih etmelerinin önemli bir nedenidir.

B.E.S.T.-Konut sertifika programının ulusal bir sertifika sistemi olmasından dolayı Türkiye'nin bölgesel önceliklerini göz önünde bulundurarak, temelde aynı ancak farklı bölgelerde farklı puanlama sistemi ile daha etkin ve verimli bir programa dönüşeceği düşünülmektedir.

Bu çerçevede, Türkiye için geliştirilen sertifika sistemlerinde, ekonomik ve sosyal etmenlerin de ekolojik etmenlerle harmanlandığı, devlet desteğinin daha fazla olduğu, kanun ve yönetmeliklere dayanan bir altyapı oluşturulması gerekliliğini göz ardı edilmemelidir. Örneğin, İngiltere' de 2006 yılından itibaren BREEAM'in tüm kamu binalarında zorunlu hale getirilmesi ve bunun devlet destekli şekilde olması, var olan sorunların çözümünde büyük bir ilerleme sağlamaktadır. Türkiye'de ise 2011 yılı itibariyle yeni yapılarda zorunlu hale getirilen, mevcut yapılarda ise 1 Ocak 2020 yılına kadar alınması için zaman tanınan Enerji Kimlik Belgesi (EKB) devlet tarafından atılan önemli bir adımdır. Enerji Kimlik Belgesi yapıların sürdürülebilirliğini 
ölçmek adına geliştirilen ölçütlerin \%30-40’ını karşılar nitelikte olduğundan, Türkiye'nin kendi sertifika sisteminin oluşturması ve geliştirilmesi için bir zemin olarak görülebilir. Bu bağlamda aşağıda sıralanan önerilerin Türkiye' deki yerel sertifika sistemi çalışmalarından B.E.S.T için ve planlanan diğer ulusal sertifika sistemi çalışmaları için yararlı olacağı öngörülmektedir:

- Ülkemizde yeşil binalar konusunda farkındalık ve bilinçlendirme çalışmaları yapılmalıdır. Çevre ve Şehircilik Bakanlığı ve Enerji ve Tabii Kaynaklar Bakanlığı liderliğinde ilgili tüm STK'lar, akademisyenler ve meslek odaları süreçte aktif rol oynamalıdır.

- Devlet- özel sektör iş birliği ile ekolojik fonlar oluşturulmalı ve yerel yönetimler de sürece eklemlenmelidir. Birleşmiş Milletler Çevre Programı, Avrupa Birliği ve Dünya Bankasınca iklim değişikliği kapsamında oluşturulan projeler zemininde işbirliğine gidilmeli ve ülkemize fon tahsisi sağlanmalıdır. Yapılacak yatırımlar sürdürülebilirlik çerçevesinde değerlendirilmelidir.

- Yeni yapılan binalardan ziyade mevcut yapı stoku üzerinden çalışmalar yapılmalıdır. Enerji tasarrufundan sağlanacak bütçe yeşil binaların teşvik edilmesi için uygulanabilecek vergi muafiyeti, vergi oranının düşürülmesi gibi çalışmalara fon sağlaması için değerlendirilebilir.

- Sertifika almaya hak kazanmış projelerin takibi sağlanmalıdır. Takibi sağlanmayan projelerin sertifika iptali gibi durumları olduğunda kamuoyu bu durumdan haberdar olamamaktadır. Sadece prestij amaçlı alınan sertifikaların önüne geçebilmek adına oluşturulacak bir takip sistemi hem vatandaş için hem sektör için hem de çevre sorumluluğu çerçevesinde ülke için yarar sağlayacaktır.

- Çevre dostu yeşil ve ekolojik binaların sertifikalandırma sürecinde önemli kriterlerin sağlanmasının ana etmenlerinden biri malzeme kullanımıdır. Bu kapsamda ülkemizde sürdürülebilir malzeme üretiminin de standartlarının belirlenip sertifikalandırılması, yapı malzemelerinin bu standartlarda üretilmesinin teşvik edilmesi de önem arz etmektedir.

- ÇEDBİK'in yeni yapılacak olan Konutlara yönelik olarak hazırlamış olduğu B.E.S.TKonut dişında, ticari binalara, mevcut binalara, okul ve hastane gibi binalara yönelik sertifika kılavuzlarının da hazırlık çalışmalarına başlanmalı ve bu çalışmalara bakanlıklar tarafından destek verilmelidir. İlgili Bakanlıklar, sertifikaların ülke genelinde kullanımını ve yaygınlaştırılmasını sağlamak amacıyla yapılacak çalışmalara destek olmalı, katılımcı ve teşvik edici rol üstlenmelidir. Ayrıca bu konudaki bilgi birikiminin kamuoyu ve ilgili paydaşlarla paylaşılması konusunda öncü olmalıdır.

- Sürdürülebilirliğin ekolojik ve ekonomik boyutlarının yanında sosyal boyutu da dikkate alınmalıdır. Sosyal sürdürülebilirlik açısından yeşil binalar ile ilgili konfor, sağlık, ulaşım gibi kriterlerin iyileştirilmesi amacıyla mevzuatlar yenilenmeli ve günümüz şartlarına uygun, güncel mevzuat ve yasal altyapı oluşturulmalıdır. Devlet bu alanda da destekleyici ve teşvik edici rol üstlenmelidir.

- Deprem bölgesi olan Türkiye'nin yerel sertifika sistemi içinde afetler konusuna ilişkin bir başlı̆̆ın eklenmesinin de önemli olduğu öngörülmektedir. Konu kapsamı sadece depremi değil, Türkiye'de sık sık yaşanan ve büyük tahribatlar veren sel felaketleri ve yangın gibi diğer doğal olaylarını da kapsayacak şekilde düzenlenmelidir. Özellikle birinci derece deprem bölgesi olan Marmara bölgesi, sık sık sel felaketi ile karşı karşıya kalan Karadeniz bölgesi ve iklim değişikliği etkisindeki Akdeniz bölgesi bunlara örnek olabilir. Bu açıdan bakıldığında, kılavuzda bölgesel öncelik başlığı altında yüksek puan 
getiren ve/veya ön koşul kabul edilen kriterlerin varlığı hem vatandaşa hem paydaşlara hem de sistemin işleyişine katkı sağlayacaktır. Devlet ve ilgili kurum ve kuruluşlar tarafından alınan bazı önlemler, yürütülen bazı yasalar ve konan yasaklar kapsamında konunun detaylı olarak ele alınmasının çok önemli olduğu söylenebilir.

- Kentlerde arazi kullanımının yanlış yönetimi sonucunda merkez tabir edilen bölgelerde yapılaşma için alan bulmak zorlaşmaktadır. Bu zorluk neticesinde yeni imar izinleri verilerek çok katlı yapıların önü açılmaktadır. Bu durum altyapı, çevre, yeşil alan gibi birçok başlıkta yeni sorunların oluşmasına yol açmaktadır. Yeşil bina projeleri ile birlikte binaların marka değerinde yaşanacak artış, yapıların maddi açıdan da değer kazanmasını sağlamaktadır. Bu durum yüklenicilerin çok katlı yapı yerine yeşil bina projelerine yönelmelerini sağlayabilecek bir etmendir. İmar planı değişikliği ile oluşacak değer artış kazancını; yoğunluk artışı yerine prestijli yeşil bina projeleri ile ikame etmek birçok başlık açısından kentsel planlamayı rahatlatacak ve sürdürülebilir kalkınmaya katkı sağlayacaktır.

Tüm bu önerilerin ayrı ayrı değerlendirilmesi süreci zorlaştıracaktır. Bu açıdan olayı bütüncül bir yaklaşım ile ele almak gerekmektedir. Sürecin planlanmasından, uygulama kriterlerine, denetiminden, geliştirilmesine kadar her açıdan organize edilmiş bir mekanizmanın varlığı konu özelinde sağlıklı bir akreditasyon oluşumunu sağlayacaktır. Denetimde kamunun rolü büyük olmalıdır ve süreç yakından takip edilmelidir. Bu noktada Çevre ve Şehircilik Bakanlığı Yapı İşleri Genel Müdürlüğü'nde oluşturulacak ve spesifik olarak yeşil bina sertifikalandırma ile kriterleri, yetkileri ve sorumlukları bu birim tarafından belirlenecek "Yeşil Bina Uzmanı" sicilini tutacak bir birimin varlığı denetim açısından etkin ve verimli bir süreç yaratacaktır.

\section{KAYNAKÇA}

Arslan, N.C. (2015). Ankara İlinde Okulda Solunan Havada Mantar Varlı̆̆ı, CO, CO2, Formaldehit ve Toluen Düzeyleri ile Öğrencilerde İlgili Olabilecek Yakınmaların Değerlendirilmesi (Yüksek 
Lisans Tezi). Hacettepe Üniversitesi Sağlık Bilimleri Enstitüsü, Çevre Hekimliği Programı, Ankara.

Baştanoğlu, E. (2017). LEED Yeşil Bina Sertifika Sistemi Uygulamalarının Değerlendirilmesi: Avrupa ve Türkiye (Yüksek Lisans Tezi). İstanbul Teknik Üniversitesi Fen Bilimleri Enstitüsü, İstanbul.

ÇEDBIK, (2019). (t.y). https://cedbik.org. (ErişimTarihi: 20. 08. 2020).

Dodge Data Analytics, (2018). World Green Building Trends 2018, Market Report, s. 9-10.

Leblebici, N., Latif, U. (2015). Yeşil Bina Sertifikalandırma Sistemlerinin İnşaat Maliyetleri ve Taşınmaz Değeri Üzerindeki Etkilerinin İncelenmesi, Düzce Üniversitesi Bilim ve Teknoloji Dergisi, 3 (2), 544-576.

Özcan, Ö., Temizbaş, A. (2010). Yeşil Bina, 1. Proje ve Yapım Yönetimi Kongresi, 29.

Somalı, B., Ilıcalı, E. (2009). LEED ve BREEAM uluslararası yeşil bina değerlendirme sistemlerinin değerlendirilmesi. IX. Ulusal Tesisat Mühendisliği Kongresi, 06-09.

Şenel, A. (2010). Sürdürülebilir bina yapım ilkelerinin ve yeni yaklaşımların incelenmesi (Yüksek Lisans Tezi), Dokuz Eylül Üniversitesi Fen Bilimleri Enstitüsü, İzmir.

Şentürk, S.H. (2014). Ekonomik ve Sosyal Araştırmalar Dergisi, 10 (10), 89.

USGBC, (2018). LEED v3 2009 Building Design and Construction Reference Guide. Washington, ABD.

World Green Building Council, (2013). The Business Case for Green Building, Market Report, 38.

Yılmaz, B., Arditi, D., Korkmaz, S. (2010). Yüksek Performanslı (Yeşil) Binalarda Bütünleşik Tasarım Sistemi, 1. Proje ve Yapım Yönetimi Kongresi, 29. 